This copy of the paper is pre-publication version submitted to the Language Learning Journal on April $16^{\text {th }} 2018$

\title{
Multilingual and monolingual children in the primary-level language classroom: Individual differences and perceptions of foreign language learning
}

\begin{abstract}
Existing research suggests that being multilingual may convey advantages for additional language learning. However, little research to date has examined the role of multiple languages in primaryschool classroom settings and in foreign language learning in particular. We investigated the learning of French by children with English as an additional language (EAL) aged 8-9 in England. The EAL children and their monolingual peers were tested on their achievement in French, their metalinguistic awareness and associative memory. Their attitudes to languages and language learning were assessed. Two French classes were observed and teachers interviewed in order to document their approach to teaching French to a mixed-language class and their perceptions of the multilingual nature of the classroom. Our findings suggest that the EAL children's multilingualism is not drawn upon as a potentially facilitative tool. English appears to be the only medium and the primary aim of instruction, with other languages assigned a subordinate role. The EAL children performed similarly to their monolingual peers on all measures, with level of English correlated with most measures. We argue that while an egalitarian treatment of all children is clearly desirable, it would be equally desirable to utilise the presence of other languages as a resource.
\end{abstract}

\section{Keywords}

Modern foreign languages, primary school, English as an additional language, multilingualism, instructed language learning

\section{Introduction}

The education system in England has seen profound changes over the past 35 years (Hofkins and Northern 2009), and this is especially true for primary foreign language instruction. The Nuffield Languages Inquiry (2000) recommended that all pupils be entitled to learn a new language from age 7 , and that $10 \%$ of curriculum time be allocated to this endeavour. The subsequent recommendation that foreign language learning should be compulsory for all children at Key Stage 2 (ages 7-11) (Rose 2009) was accepted by the then government, rejected by the 2010 coalition government, but eventually became a statutory requirement in September 2014 for all state primary schools in England. This policy is aimed at addressing the shortage of language skills in the UK, which is ranked among the lowest in Europe (Lanvers and Coleman 2017), and the marked decrease in the take-up of foreign languages at GCSE (General Certificate of Secondary Education) level, following the reduction of the period of compulsory foreign language study to the first three years of secondary school (ages 11-14) in 2004 (Dearing and King 2006; Rose 2009).

While offering foreign language instruction at primary level is certainly desirable in principle, the learning and teaching contexts in primary schools in England are complex. In particular, many primary schools are no longer monolingual English, but educate a mixture of monolingual English children and children with English as an additional language (EAL). Present figures show that there are over one million pupils in UK schools for whom English is an additional language (Naldic 2018) In "primary schools, $20.1 \%$ of pupils are exposed to a language known or believed to be other than 
English in their home, a figure which has been steadily rising since 2006". (Department for Education 2016, 10).

In the following, we present findings from an exploratory study that investigated if, and to what extent, being multilingual affords EAL children any advantages in learning a modern foreign language (MFL) in the limited-input setting of a primary-school classroom in England. We specifically examined the role of children's metalinguistic awareness, their associative memory/vocabulary learning ability, and their attitudes towards languages and language learning. We also examined how EAL children's multilingualism was perceived by their teachers, their monolingual classmates and the EAL children themselves, as well as whether their multilingualism was used as a resource in MFL classes.

\section{Background}

\section{EAL children in schools in England}

In the current version of the national curriculum at both primary and secondary level, in addition to being a curriculum subject, English is the dominant language of input and production as well as the dominant language of assessment for teachers and students. English, or more accurately Standard English, is the desired medium through which successful acquisition of curriculum content is to be achieved and measured:

Pupils should be taught in all subjects to express themselves correctly and appropriately and to read accurately and with understanding. Since Standard English, spoken and written, is the predominant language in which knowledge and skills are taught and learned, pupils should be taught to recognise and use Standard English. (Qualifications and Curriculum Development Agency, URL: http://archive.teachfind.com/qcda/curriculum.qcda.gov.uk/keystages-1-and-2/general-teaching-requirements/use-of-language/index.html - accessed 27/10/17).

In terms of the curriculum, successful use and acquisition of Standard English is a learning goal for all pupils, and it is therefore the job of teachers to ensure that students are provided with appropriate learning conditions which accordingly offer ample exposure to, modelling and usage of Standard English. A consequence of such a policy is that it ultimately positions all teachers as language teachers and all students as language learners, regardless of their background and knowledge of or about the language (Leung 2010, 2016). This framing of teachers and students is particularly interesting with regard to learners for whom English is an additional language, as it has direct implications for the ways in which EAL learners are conceptualised within the curriculum.

With Standard English as the dominant language goal for everyone, students operating with EAL are essentially facing the same task as their monolingual peers in that everyone needs to learn this variety of English successfully. Following the assumption that Standard English is best acquired through the mainstream classroom, EAL is not seen as a distinct curriculum subject, but is what Leung (2010) has described as a diffused curriculum concern. In this regard, EAL students are no different from their monolingual peers; they simply may need to acquire more English:

The ability of pupils for whom English is an additional language to take part in the national curriculum may be ahead of their communication skills in English. Teachers should plan learning opportunities to help pupils develop their English and should aim to provide the support pupils need to take part in all subject areas (QCDA 2017). 
The national curriculum can best be described as being monolingual in its orientation to teaching and learning. At a societal level and in government policy rhetoric, linguistic diversity is celebrated and valued as something that is beneficial to schools and the wider community, but it is not necessarily valued or conceptualised as a tool for learning within the classroom (Author 1; Leung 2010). In this regard, it is (Standard) English that is prized and required and which becomes the overriding concern with respect to the learning needs of EAL students.

Given the introduction of MFL provision into the state primary-school curriculum in England in 2014, the situation has become more complex. In addition to aiming for proficient use of Standard English, pupils encounter a foreign language for the first time in a formal classroom setting. Whereas the learning goal could again be described as similar for both monolingual and EAL children in the sense that they all start from zero in principle - though this will of course depend on the MFL chosen there is a crucial difference in the provision of input. As English is the dominant medium of instruction as well as a curriculum subject, children are exposed to plenty of (Standard) English. By contrast, children in primary schools in England are only offered very limited MFL input, that is, less than one hour per week in nearly $90 \%$ of primary schools, and often as little as 30 minutes per week (Board and Tinsley 2017,28). While children's language learning is generally successful in a context that provides both extensive and intensive long-term exposure, it is more likely to be subject to individual differences in instructed minimal-input settings such as the MFL context at primary-school level.

\section{Factors affecting children's instructed foreign language learning}

Individual learner differences refer to psychological variables that either have been shown to impact on or are thought to have an influence on language learning. Indeed, there is ample evidence for the role of a number of individual difference variables in instructed adult language learning (Dörnyei 2005; Dörnyei and Skehan 2003), with most research to date focusing on cognitive factors such as language learning aptitude and affective or conative factors such as motivation. In the area of child language learning, the body of available research is smaller. Language learning aptitude, which refers to the ability to learn foreign languages quickly and with ease, is dynamic in young learners who are still developing cognitively (Suárez and Muñoz 2011). Nevertheless, we have convincing evidence that measures of aptitude can predict achievement in children learning in instructed settings (Kiss 2009; Kiss and Nikolov 2005; Muñoz 2014; Authors 3 and 4; Sáfár and Kormos 2008).

Metalinguistic awareness refers to the ability to separate language form from language function, to treat language as an object of study and reflection (Gombert 1992), or, to put it slightly differently, to be able to look at language rather than through it (Cummins 1987). Like language learning aptitude, metalinguistic awareness develops as children mature and, if they benefit from education, as they acquire literacy skills (Bialystok, 2001). Empirical research has shown that metalinguistic awareness is positively associated with foreign language development in children (Author 3; Authors 3 and 4).

Studies with a cognitive-developmental orientation as well as educational research suggest that on average, bi- or multilingual children tend to have more developed metalinguistic abilities than monolingual children. Researchers taking a cognitive-developmental approach typically compare the performance of monolingual and bilingual children who are matched for age, non-verbal intelligence, educational and socioeconomic background on measures tapping executive function, i.e. the capacity for selectively focusing attention, monitoring, and inhibiting information that is irrelevant to a given task. Cumulative findings show that bilingual children tend to outperform matched monolingual comparison groups in terms of executive control (Bialystok and Craik 2010; Bialystok, Craik, and Luk 2012; Bialystok and Martin 2004; Poarch and van Hell 2012). This so-called 
bilingual advantage in executive function is thought to arise from the need of having to manage more than one language. The advantage is thought to build up over several years, so it is normally present only in early, long-term bilinguals, but not in young MFL learners, for instance. Importantly, executive function is the cognitive capacity underlying metalinguistic abilities, in the sense that these abilities require an individual to access analysed knowledge via controlled processes (Bialystok 1994, 2001; Bialystok and Ryan 1985), as exemplified by the need to inhibit a focus on meaning in order to focus on form, for example.

Researchers interested in language education have argued that multilinguals differ qualitatively from both monolinguals and bilinguals due to their experience with more than one additional language.

This is expected to affect not only their cognition, but may also impact on affective, motivational and personality variables. For instance, it has been proposed that multilinguals may be more adept at divergent thinking, may be more communicatively sensitive and, importantly for the argument presented here, will exhibit enhanced metalinguistic awareness (Baker 2006; Jessner 1999, 2006).

Learners' attitudes towards languages in general and the language learning process more specifically is another individual difference variable that is sometimes investigated together with cognitive abilities. Researchers hypothesise that more positive attitudes, greater enjoyment of learning, greater willingness to learn and greater confidence in one's own abilities will be related to language learning success. In the area of child learning, the evidence is rather mixed, however (Cenoz 2003; Author 3). A possible reason for this is that children tend to display positive attitudes throughout, showing relatively little variation. Such a situation may help explain why correlations with achievement are not necessarily found.

\section{Research issues}

In summary, existing research suggests that individual differences between learners are likely to play a role in children's instructed MFL learning in a limited-input classroom setting. While there is no direct empirical evidence that would lead one to assume that multilingual children will have higher language learning aptitude or will display more positive attitudes, findings to date lead to the hypothesis that they may have superior metalinguistic abilities compared with their monolingual peers. In addition, it can be argued that in the primary-school context in England, both monolingual and EAL children are faced with similar learning goals, in the sense that the language-related objectives of the national curriculum call for the development of proficiency in Standard English and the learning of a new MFL. Any differences in terms of the MFL learning task could either be seen as purely quantitative (Leung 2010, 2016), or they may be conceptualised as qualitative (Jessner 1999, 2006), depending on the researcher's outlook. With a view to children's MFL success, both approaches would arguably lead to the same hypothesis, with multilingual children expected to be at an advantage (if differences are qualitative), or at least not at a disadvantage (if differences are quantitative). With a view to children's and teachers' perceptions of EAL children's MFL learning and any facilitative role being assigned to EAL children's multilingualism, a perception of differences as quantitative may result in EAL children being seen and treated as no different from their monolingual peers, while a perception of differences as qualitative may result in EAL children being seen and treated differently, whether positively, negatively or a combination of both.

In order to explore these issues, we posed the following research questions:

(1) Does being multilingual facilitate or impede the foreign language learning process? In particular, what is the role of individual learner differences? 
(2) How do EAL children, monolingual children and their teachers perceive and relate to the learning of foreign languages?

(3) Do teachers and other children draw on EAL children's multilingualism, and if yes, how?

\section{Methodology \\ Case study school and participants}

The present study was carried out in a mainstream co-educational primary academy with over 500 pupils, situated in a large English commuter town close to the town centre. In terms of socioeconomic status, the area in question is less affluent. The most recent OFSTED report classified the school as requiring improvement. The report highlighted that children between the end of Key Stage 1 and the end of Key Stage 2 made average progress in reading, below average progress in maths, and well below average progress in writing, as shown by publicly available data for the school year 2015-2016. Interestingly, given its geographic location in the east of England, the proportion of EAL children at the school is close to $50 \%$, putting it well above the national average of about $20 \%$, as reported above.

The school displays a very welcoming ethos towards children from different backgrounds and cultures and appears to be supportive of EAL children. Throughout the school, attractive multilingual wall displays can be found, the reception area has a multilingual interactive school information board for parents, and the school has a multilingual school song. The school has a specialist full-time EAL co-ordinator who, together with an assistant, is responsible for offering dedicated EAL learning support either in class or in small pull-out classes convening in a dedicated EAL teaching room. The EAL coordinator is also the MFL coordinator for the whole school, overseeing the delivery of the MFL curriculum.

In order to address our research questions, we took a mixed-methods approach drawing on both quantitative and qualitative data collection tools. The research took place over the course of one week in March 2017. In order to make maximum use of our time and limit any disruption to the dayto-day running of the school and classes, some measures (see below) were administered on our behalf by the class teachers and the MFL/EAL coordinator before we arrived on site at the school. The remaining tests and procedures were conducted by different members of the research team over the course of the week in the school.

Our participants were 49 children in two Year 4 classes (ages 8-9) for whom a 30-minute French lesson was scheduled once a week. The participating classes were labelled Alpha ( $N=25 ; 13 \mathrm{EAL}$ children) and Beta ( $N=24 ; 11$ EAL children). None of the participating children had French as their first language, and all children were able to participate in the French lessons. The EAL children had a variety of language backgrounds, with home languages reported as Portuguese ( 5 children), Romanian (5), Kurdish (4), Farsi (3), Polish (3), Albanian (1), Arabic (1), Bengali (1) and Romani (1). Eleven EAL children reported speaking both their home language and English with family members, and some children reported exposure to additional languages beyond their home language and English. Three children were attending a Saturday school in which they studied their home language, and several children reported exposure to other languages at previous schools. In addition to the children, further participants also included the two class (Alpha and Beta) teachers, and the MFL/EAL coordinator.

\section{Data collection, instruments and procedures}


All children completed background and attitude questionnaires, a test of French proficiency, a test of metalinguistic awareness, and a test of associative memory that is part of a language learning aptitude battery. Furthermore, all children participated in individual interviews. In addition, we interviewed the two class teachers and the MFL/EAL coordinator, and we observed one French lesson per class teacher. The instruments and procedures are described in detail in what follows.

Data collection began with the background questionnaire and the attitude questionnaire. The latter comprised six closed-ended items with a 5-point answer scale ranging from 'definitely no' to 'definitely yes'. We asked the children questions on the following: whether they thought they did well at their school work, if they thought they were good at languages, if they thought learning a language was fun, if they looked forward to learning other languages, whether they enjoyed their French lessons, and if they found French easy. A final, open-ended item asked them to complete the statement 'I think learning French is...' with an adjective or adjectives of their choice. In addition, the children completed a short background questionnaire asking about their language learning histories. These questionnaires were handed out by the class teachers and/or the MFL/EAL coordinator before we visited the school.

The next phase of data collection involved different members of the research team going into the school over the course of a week and administering the remaining tests and carrying out interviews and observations. The MFL/EAL coordinator worked with the class teachers to develop a timetable for the various data collection sessions and made it possible for children to leave the classroom to undertake tests and to take part in the interviews. The teachers also arranged times for two members of the research team to observe them teaching one of their French classes for 30 minutes each and to participate in follow-up interviews with them afterwards.

French lessons at the school largely rely on the video-based Rigolo programme (Rigolo 2018) that provides all materials ready for use by non-specialist teachers. The test of French proficiency was specifically developed for the study, based on the content of Rigolo that we expected classes to have covered up to the point of data collection: four terms of French at 30 minutes per week, translating into approximately 22 hours of input. The test assessed listening by means of vocabulary-based and sentence-based subtests using four-way multiple-choice items in picture format; reading by means of simple reading comprehension tasks with answers to be written in English or, for the EAL children, in the child's home language, if preferred; and grammar by means of three-way multiple-choice items targeting plural of nouns, grammatical gender, negation and adjectival agreement.

The test of metalinguistic awareness consisted of tasks taken from the test of metalinguistic awareness developed by Author 3 . The tasks in question draw on an artificial mini-language invented for the test and target simple metalinguistic terminology, subject and object case marking, adjective placement, orthographic similarities between words in a class, plural marking on nouns and verbs, and adjectival agreement by gender and number. The test of metalinguistic awareness (Cronbach's alpha $=.886$ ), the test of French proficiency (Cronbach's alpha $=.780$ ) and the attitude questionnaire (Cronbach's alpha $=.639$ ) showed good reliability. These measures as well as the background questionnaire were group-administered.

Members of the research team administered the test of associative memory/vocabulary learning ability, which was the computer-based LLAMA B from the LLAMA aptitude test suite (Meara 2005; Rogers et al. 2016). The test is administered individually and is designed to assess test takers' ability to learn and retain new vocabulary in an invented language. During a two-minute study phase, the test taker tries to learn a set of picture-word associations by clicking on pictures of alien creatures. Each creature is associated with a name in an unknown language, which appears on the screen until 
the test-taker clicks on another creature. During the untimed test phase, a name appears in the centre of the screen, and the test-taker must choose the creature it refers to.

Two 30-minute French classes were observed, taught by the two class teachers. The observations focused on which language(s) were used by the teachers and the children (French, English, other languages); whether French was compared to English or any other language; whether metalinguistic information was used; whether any observable learning strategies were used by the children; whether EAL children's multilingualism was drawn on in any way; and anything else noteworthy.

Members of the research team conducted individual semi-structured interviews with the two class teachers and the MFL/EAL coordinator as well as with all the children. The interview questions for the teachers and the MFL/EAL coordinator focused on current and past experiences with languages, language learning and language teaching, their perceptions of the children's language learning and any observed or perceived differences between the EAL children and the monolingual children, and how these are dealt with. The interview questions for the children focused on what languages they know, what languages they like, how they use their language(s), whether they find language learning easy or difficult, and how they go about language learning.

\section{Results and discussion}

\section{Comparison of EAL and monolingual children}

Our first research question asked whether being multilingual would facilitate or impede the foreign language learning process, and in particular, what the role of individual learner differences might be in this process. In order to address the question, we compared the attitudes and test performance of the EAL children in the sample $(\mathrm{N}=24)$ with the attitudes and performance of the monolingual English children ( $N=25)$. Figures 1-4 give a descriptive overview of children's attitudes based on their closed-ended questionnaire answers, their French proficiency, metalinguistic awareness and associative memory test scores.

[Insert Figures 1-4 here ]

Overall, the boxplots suggest that the children had very positive attitudes towards learning French, with the monolingual group showing slightly more variance than the EAL group (Figure 1). In terms of test performance, children from both groups showed quite similar levels of French proficiency and metalinguistic awareness, although the EAL children displayed greater variance on both measures (Figures 2 and 3). With regard to vocabulary learning ability, both groups performed equally poorly (Figure 4), which suggests that the LLAMA B was very challenging for the children, who were at the lower age band of recommended test use (Rogers et al. 2016).

In keeping with the exploratory nature of the study, we performed a multivariate analysis of covariance (MANCOVA) on the entire data set $(N=49)$ in order to get an overview of any effects and/or interactions between variables. EAL status (multilingual vs. monolingual English) and gender (male vs. female) were entered as fixed factors, and class (Alpha vs. Beta) was set as a covariate to control for possible teacher effects. French proficiency, metalinguistic awareness, associative memory and attitudes were entered as the dependent variables.

Few statistical effects and no interactions were identified. We found a significant effect of gender in that the analysis revealed that girls did better than boys on the test of French proficiency, although the effect size is small: $F(1,42)=8.476, p=.006$, partial eta squared $=.168$. Girls also reported more positive attitudes than boys, but again with a small effect size: $F(1,42)=7.148, p=.011$, partial eta squared $=.145$. Gender had no statistical effect on metalinguistic awareness or associative memory, 
and there was no interaction with EAL status. In addition, we found a marginal effect of EAL status, with monolingual children showing a trend towards better performance on the test of metalinguistic awareness: $F(1,42)=3.735, p=.060$, partial eta squared $=.082$. There was no effect of EAL status on French proficiency, associative memory or attitudes, and no interaction with gender, as already indicated.

In order to address our first research question in more detail, we performed correlational analyses focused on French proficiency. In the sample as a whole, we found significant positive correlations of moderate to medium strength between French proficiency and all the individual difference variables measured, that is, metalinguistic awareness: $r=.501^{* *} p=<.001$; associative memory: $r=.446^{* *}, p$ $=.002$; and attitudes: $r=.346^{*}, p=.016$. We then ran correlations for the groups of EAL and monolingual children separately. The results are shown in Table 1.

[Insert Table 1 here]

The results in Table 1 suggest that the EAL group was driving the correlational pattern observed for the sample as a whole. In other words, the EAL group shows the expected correlational pattern, according to which greater metalinguistic awareness and better associative memory are associated with increased French proficiency. By contrast, the monolingual group does not show this pattern: metalinguistic awareness and associative memory are not statistically related to $L 2$ French proficiency. Attitude does not correlate with French proficiency in either group, so this variable has been omitted from Table 1. The most likely explanation for this is the weak coefficient observed for the sample as a whole; once the cohort was split into two smaller groups, there was no longer sufficient statistical power for the relationship to show.

A possible interpretation of the contrasting correlational patterns by group is that the EAL children were challenged in the French classes. Thus, we can observe the expected mutually reinforcing cycle of greater metalinguistic awareness and associative memory allowing for improved development of French proficiency, and probably vice versa. As the French classes require the EAL children to learn a new language through English, the potential challenge can be appreciated. Conversely, our results suggest that in the monolingual group, individual differences do not matter for improved development of French proficiency. This may suggest that the French classes cater for the weaker monolingual children. Lower levels of metalinguistic awareness and associative memory are no hindrance to French achievement, such as it is, and higher levels do not convey the expected advantage.

Finally, we examined the role of EAL children's level of English as reflected in the school's assessment carried out in accordance with the UK Department for Education requirements. The school classifies EAL children on a scale from Level A ('New to English') to Level E ('Fluent'). We found that level of English was significantly correlated at a medium level of strength with the individual difference variables of metalinguistic awareness $(r=.529 * *, p=.008)$ and associative memory $\left(r=.553^{* *}, p=.005\right)$. The correlation approached significance for French proficiency $(r=$ $.396, p=.055)$. These results indicate that a higher level of English is associated with better metalinguistic awareness, better associative memory and (marginally) better French proficiency. However, it should be borne in mind that the test instructions were in English in all cases, so we cannot exclude a certain task effect in this case.

\section{Perceptions of multilingualism and foreign language learning}

The second and third research questions asked, respectively, how EAL children, monolingual children and their teachers perceive and relate to the learning of foreign languages, and whether and how 
teachers and other children draw on EAL children's multilingualism. These questions were addressed primarily on the basis of the interview and class observation data, which were subjected to a content analysis.

The interviews with the children brought out a number of viewpoints. Despite their young age, all children were aware of the multilingual nature of the school and their classrooms, and all were positive about the notion of multilingualism. They commented on the social dimension of knowing different languages, that is, to make friends and help others in and outside of school. Nearly all children further said that they liked learning French, but found it difficult; pronunciation and spelling in particular were seen as challenging:

"Because the words are different to, um, how you speak in English." (Learner 3)

"Because I need to remember spellings [...] the hard bit is remember, is actually remembering the words and saying the words." (Learner 19)

"Sometimes it's difficult because you can't really pronounce the words that much." (Learner 34)

Interestingly, when asked what languages they know, most monolingual children mentioned French, whereas multilingual children did not list it among the languages they said they knew. This may suggest that multilingual children were clearer about what knowing a language actually means and were more aware that they knew very little French yet. Finally, for both monolingual and multilingual children, their understanding of French as a language did not go beyond a set of new words to learn. This perception appears to be in keeping with the characteristics of the French lessons they had experienced so far, as detailed below. Many children also commented that learning French was harder than learning English.

During the post-observation interviews, both class teachers explained that the language of classroom management and instruction was English, and that the learners' home language was better used at home. Teacher 2 expanded on this point:

"I guess they're encouraged to speak their home language at home, but during the day we would encourage them to speak English. But, um, we don't want them to lose the languages that they've learnt. Um, yeah, so they don't tend to speak their home language at school so much, apart from when we've got new children and then there's a lot more going on."

Both teachers saw learning French as a leveller because both EAL and monolingual children in their classes started from scratch and "everyone is on a plain level field" (Teacher 1 ). The teachers seemed to have low expectations in terms of their pupils' academic achievement in learning French and argued that the 'real' learning of French would take place in secondary school. The class teachers also commented on the Rigolo French programme, which they found easy to use as nonspecialists and which their pupils enjoyed. However, they expressively argued that there is insufficient time for learners to progress as French "is definitely not a priority" in the busy school curriculum and "is fairly unspecific" (Teacher 2). The extract from Teacher 1 below is illustrative of this point:

"[Rigolo is] not the greatest. It's easy to use. It's got the fun characters that the children enjoy. If it was, I think for the teachers who don't know French or who don't enjoy French it's easy to use. I quite like doing something more, but with everything else in the timetable there's no time. It's kind of a quick fix." 
The classroom observations suggested that the teachers did not draw on the EAL children's multilingualism during the French classes. English was widely used throughout the French lessons, and French was used primarily for individual or choral drilling of individual words or short phrases produced by the class teacher or a character in the Rigolo programme. Some translation of French words and phrases and some writing of individual words in French also took place. Comparisons between French, English, and the EAL children's home languages were not made during the observed sessions. Although the children were enthusiastic about the French lessons and remained engaged throughout, the use of language as an object of study or as a communicative tool was absent from the observed French classes; the use of French focused exclusively on the rote memorization of individual words and short phrases.

\section{The positioning of EAL children}

Taken together, the findings arising from the quantitative and qualitative analyses suggest that the EAL children in the two classes we studied were not at any advantage compared with their monolingual peers. There were no differences in French proficiency or attitudes between the two groups, and somewhat unexpectedly (Jessner 1999, 2006), the monolingual children showed a trend towards outperforming the multilingual children on the measure of metalinguistic awareness, although it must be borne in mind that the test instructions were in English. In addition, in the MFL classes we observed, the EAL children's home languages were never used or drawn upon to provide (meta)linguistic illustrations or highlight cross-linguistic similarities or differences. At no time were the EAL children positioned as language experts whose home languages may provide an opportunity to reflect on language, or who may have developed language learning strategies that could be shared with the class. This approach provides a marked contrast with the positive ethos towards multilingualism which the school projects through its displays, school song, etc., and the overall very positive attitudes all children appeared to hold towards multilingualism and French language learning. The only indications of a special status of the EAL children were found in these children's apparently superior metacognitive awareness in that they tended to realise more readily than their monolingual peers that they did not really know much (any?) French yet, and in the school's readiness to draw on an EAL child's home language to help a new pupil with the same home language settle in.

Our combined findings further suggest that English had clear primacy in the children's education at the case study school. In particular, it was the exclusive language of instruction in the observed MFL classes, which probably helps explain the trend towards a correlation between EAL children's level of English and their achievement in French. The facts that the class teachers saw English as the school language, that they were not MFL specialists, and that MFL teaching and learning played only a very minor role in the school's curriculum all seemingly helped enforce a monolingual norm that does not see or treat multilingual children as special or qualitatively different. Instead, a perception of purely quantitative differences (EAL children may need to learn more English than their monolingual peers) (Leung 2010, 2016) or of no differences (all children are on a level playing field in the MFL class) appears to be in evidence. It is not clear whether this perception of all children as being essentially equal and any behaviour and discourse patterns associated with this perception are responsible for the very similar results obtained by the EAL and monolingual children on the various quantitative measures we administered, or whether children's performance and the actions and discourses they encounter more likely mutually reinforce each other over time.

\section{Conclusion}


The present study has revealed a complex interplay of factors characterising the learning context in which EAL children in an English primary school find themselves. Although our findings are based on data from two classes at a single school and can therefore not be generalised, they suggest that EAL children are seen and treated no differently from their monolingual peers, and that in most respects these children behave and perform accordingly. While equal treatment is clearly desirable for all students, the cumulative findings from previous research demonstrating advantages of bi- or multilingual children in terms of metalinguistic abilities would seem to indicate that potentially valuable knowledge, skills and experiences of these learners remain under-explored and underutilised in the primary school classroom. Further research aimed at identifying the conditions under which primary-school MFL classes might usefully and realistically draw on the potential assets that their multilingual learners can offer would therefore be desirable.

\section{References}

Baker, C. 2006. Foundations of bilingual education and bilingualism (4th ed.). Clevedon: Mutilingual Matters.

Bialystok, E. 1994. Analysis and control in the development of second language proficiency. Studies in Second Language Acquisition, 16, 157-168.

Bialystok, E. 2001. Bilingualism in development: Language, literacy, and cognition. Cambridge:

Cambridge University Press.

Bialystok, E., and Craik, F. I. M. 2010. Cognitive and linguistic processing in the bilingual mind.

Current Directions in Psychological Science, 19(1), 19-23.

Bialystok, E., Craik, F. I. M., and Luk, G. 2012. Bilingualism: Consequences for mind and brain. Trends in Cognitive Sciences, 16(4), 240-250.

Bialystok, E., and Martin, M. M. 2004. Attention and inhibition in bilingual children: Evidence from the dimensional change card sort task. Developmental Science, 7(3), 325-339.

Bialystok, E., and Ryan, E. B. 1985. Toward a definition of metalinguistic skill. Merrill-Palmer Quarterly, 31(3), 229-251.

Board, K., and Tinsley, T. 2017. Language Trends 2016/17: Language Teaching in Primary and Secondary Schools in England. Survey Report. Manchester: British Council. 
Cenoz, J. 2003. The influence of age on the acquisition of English: General proficiency, attitudes and code-mixing. In María del Pilar García Mayo and María Luisa García Lecumberri eds. Age and the acquisition of English as a foreign language, 77-93. Clevedon: Multilingual Matters.

Cummins, J. 1987. Bilingualism, language proficiency, and metalinguistic development. In Peter Homel, Michael Palij, and Doris Aaronson eds. Childhood bilingualism: Aspects of linguistic, cognitive, and social development, 57-73. Hillsdale, NJ: Erlbaum.

Dearing, R. and King, L. 2006. Languages review: consultation report. London: DfES.

Department for Education 2016. Schools, pupils and their characteristics: January 2016. SFR

20/2016. Crown Copyright.

Dörnyei, Z. 2005. The psychology of the language learner: Individual differences in second language acquisition. Mahwah, NJ: Erlbaum.

Dörnyei, Z., and Skehan, P. 2003. Individual differences in second language learning. In Catherine Doughty and Michael Long eds. The handbook of second language acquisition, 589-630. Malden, MA: Blackwell.

Gombert, J. E. 1992. Metalinguistic development. Hemel Hempstead: Harvester.

Hofkins, D., and Northen, S. 2009. Introducing the Cambridge Primary Review. Cambridge: University of Cambridge Faculty of Education.

Jessner, U. 1999. Metalinguistic awareness in multilinguals: Cognitive aspects of third language learning. Language Awareness, 8(3\&4), 201-209.

Jessner, U. 2006. Linguistic awareness in multilinguals: English as a third language. Edinburgh: Edinburgh University Press.

Kiss, C. 2009. The role of aptitude in young learners' foreign language learning. Edited by, Marianne Nikolov, The age factor and early language learning, 253-276. Berlin: Mouton de Gruyter. 
Kiss, C., and Nikolov, M. 2005. Developing, piloting, and validating an instrument to measure young learners' aptitude. Language Learning, 55(1), 99-150.

Lanvers, U., and Coleman, J. A. (2017). The UK language learning crisis in the public media: a critical analysis. The Language Learning Journal, 45(1), 3-25.

Leung, C. 2010 English as an Additional Language: Distinct Language Focus or Diffused Curriculum Concerns? Language and Education, 15(1), 33-55.

Leung, C. 2016. English as an additional language - a genealogy of language-in-education policies and reflections on research trajectories. Language and Education, 30(2), 158-174.

Meara, P. 2005. Llama Language Aptitude Tests. University of Wales Swansea.

Muñoz, C. 2014. The association between aptitude components and language skills in young learners. In Miroslaw Pawlak and Larissa Aronin eds. Essential topics in applied linguistics and multilingualism: Studies in honour of David Singleton, 51-68. Cham: Springer.

Naldic. 2018. (URL: https://naldic.org.uk/the-eal-learner/research-and-statistics/\#eal-learners-inschools - accessed 08/03/18).

Nuffield Languages Inquiry 2000. Languages: the next generation. London: The Nuffield Foundation.

Poarch, G. J., and van Hell, J. G. 2012. Executive functions and inhibitory control in multilingual children: Evidence from second-language learners, bilinguals, and trilinguals. Journal of Experimental Child Psychology, 113, 535-551.

QCDA 2017, URL: http://archive.teachfind.com/qcda/curriculum.qcda.gov.uk/key-stages-1-and2/general-teaching-requirements/including-all-learners/index.html - accessed 27/10/17).

Rigolo 2018 URL: https://global.oup.com/education/content/primary/series/rigolo/?region=uk - 
accessed 19/03/18).

Rogers, V., Meara, P., Aspinall, R., Fallon, L., Goss, T., Keey, E., and Thomas, R. (2016). Testing aptitude: Investigating Meara's 2005 LLAMA tests. EuroSLA Yearbook, 16, 179-210.

Rose, J. (Ed.). 2009. The Independent Review of the Primary Curriculum: Final report: Department for Children, Schools and Families. URL:

http://www.educationengland.org.uk/documents/pdfs/2009-IRPC-final-report.pdf .

Suárez, M. d. M., and Muñoz, C. 2011. Aptitude, age and cognitive development: The MLAT-E in Spanish and Catalan. In Leah Roberts, Gabriele Pallotti, and Camilla Bettoni eds. EuroSLA Yearbook, Vol. 11, 5 29. Amsterdam: John Benjamins.

Sáfár, A., and Kormos, J. 2008. Revisiting problems with foreign language aptitude. IRAL, 46, 113136. 
Figure 1: Children's attitudes (higher scores are indicative of more positive attitudes)

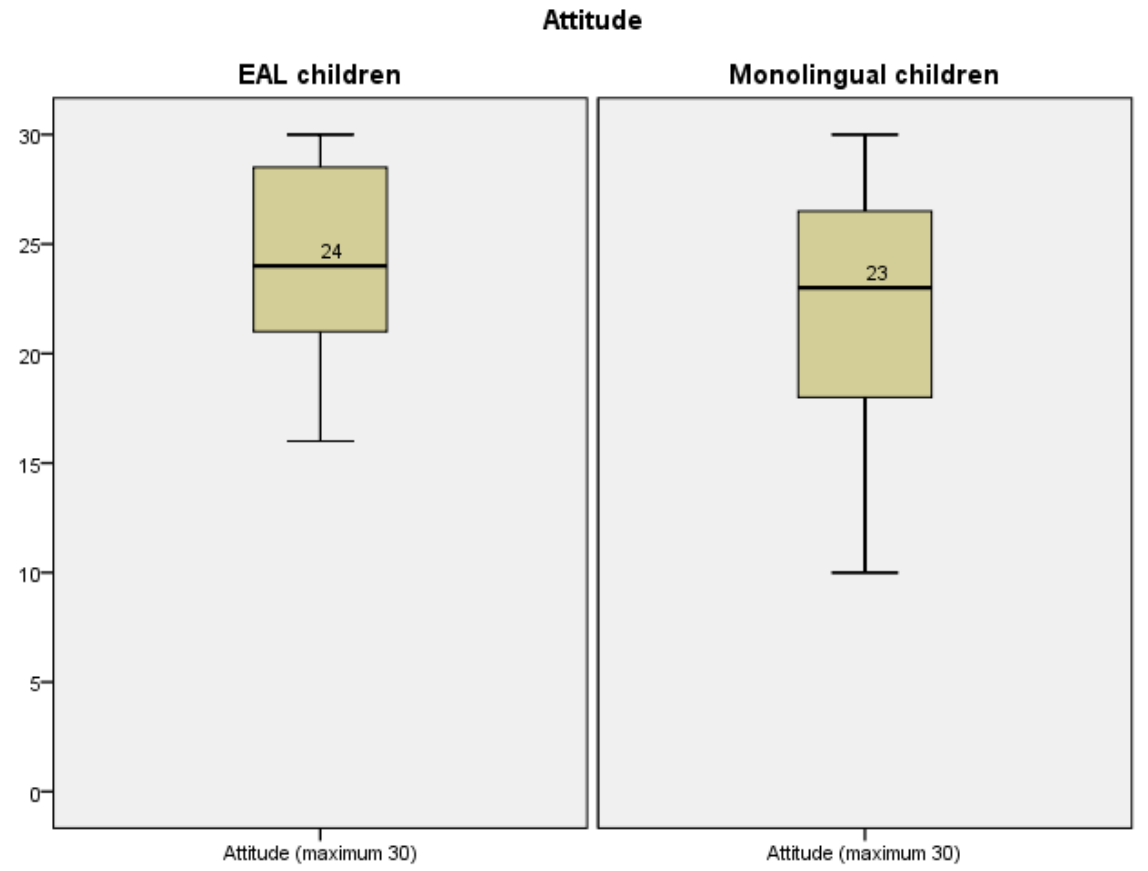

Figure 2: Children's French proficiency

French Language Proficiency

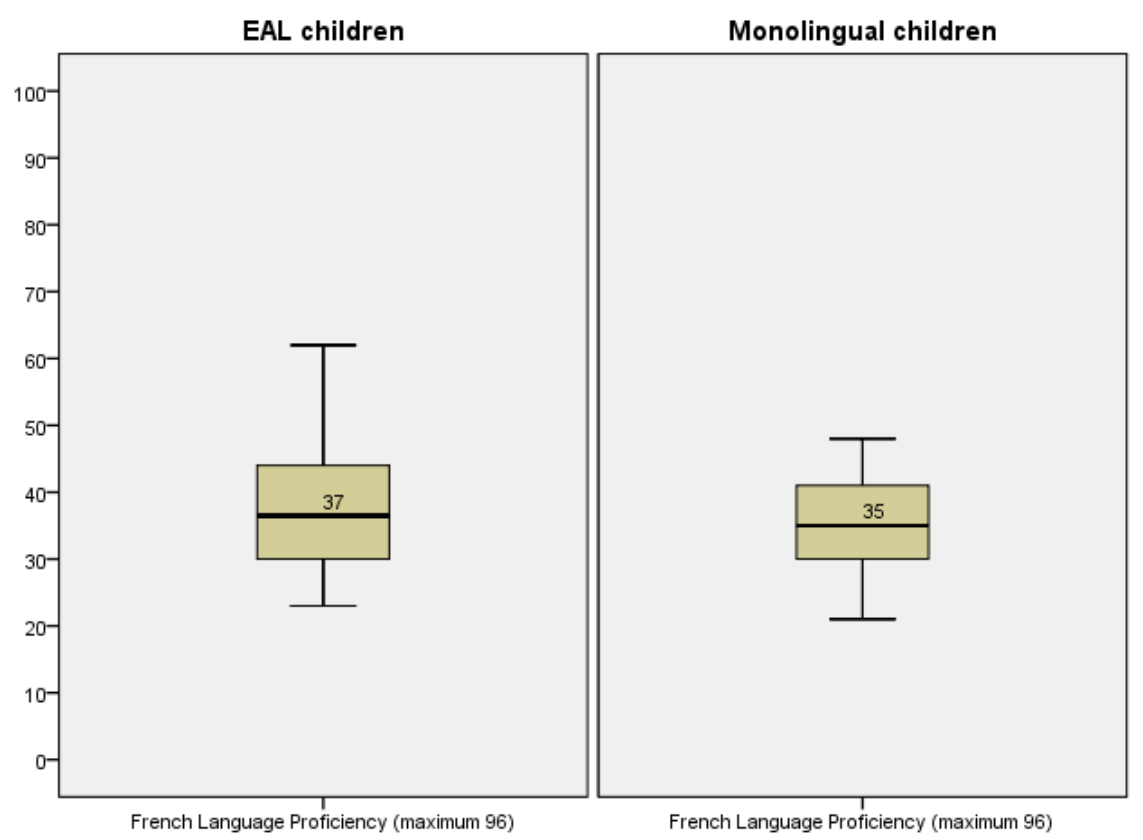

Figure 3: Children's metalinguistic awareness 
Metalinguistic Awareness

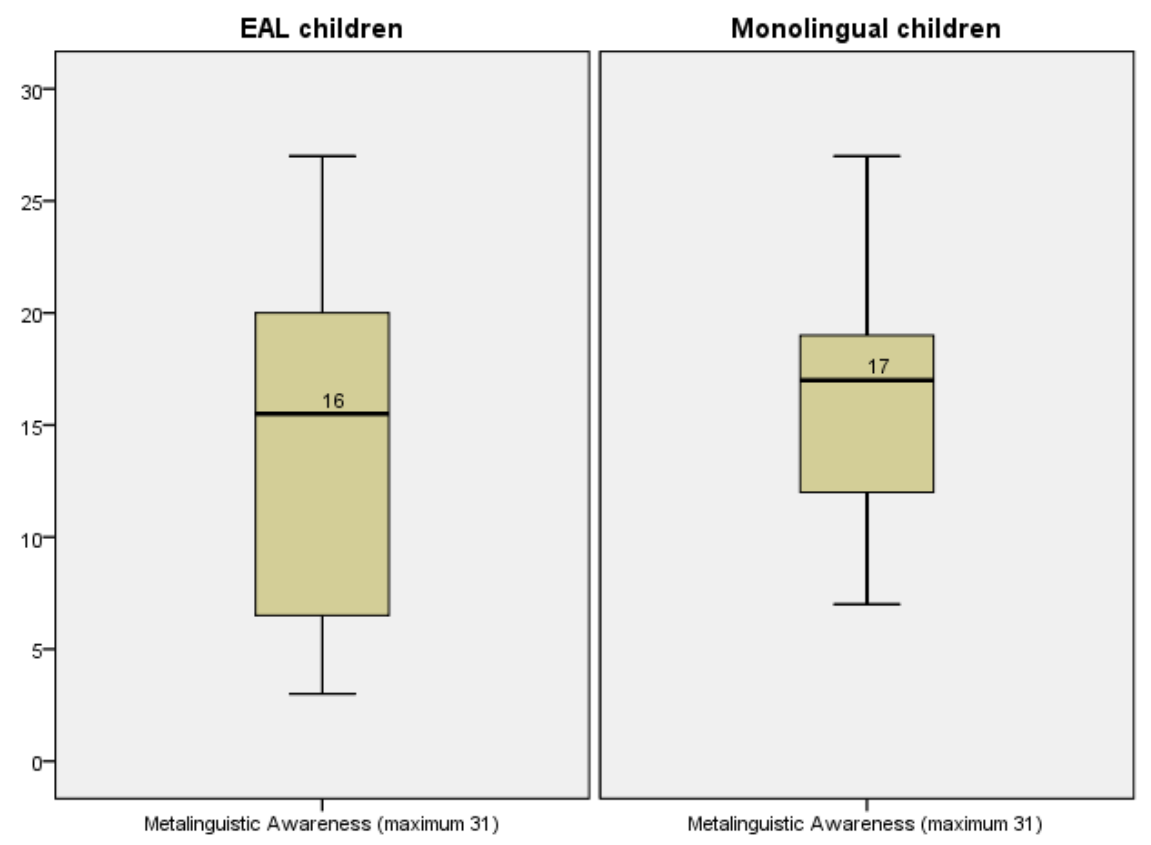

Figure 4: Children's associative memory

Aptitude Vocabulary Learning

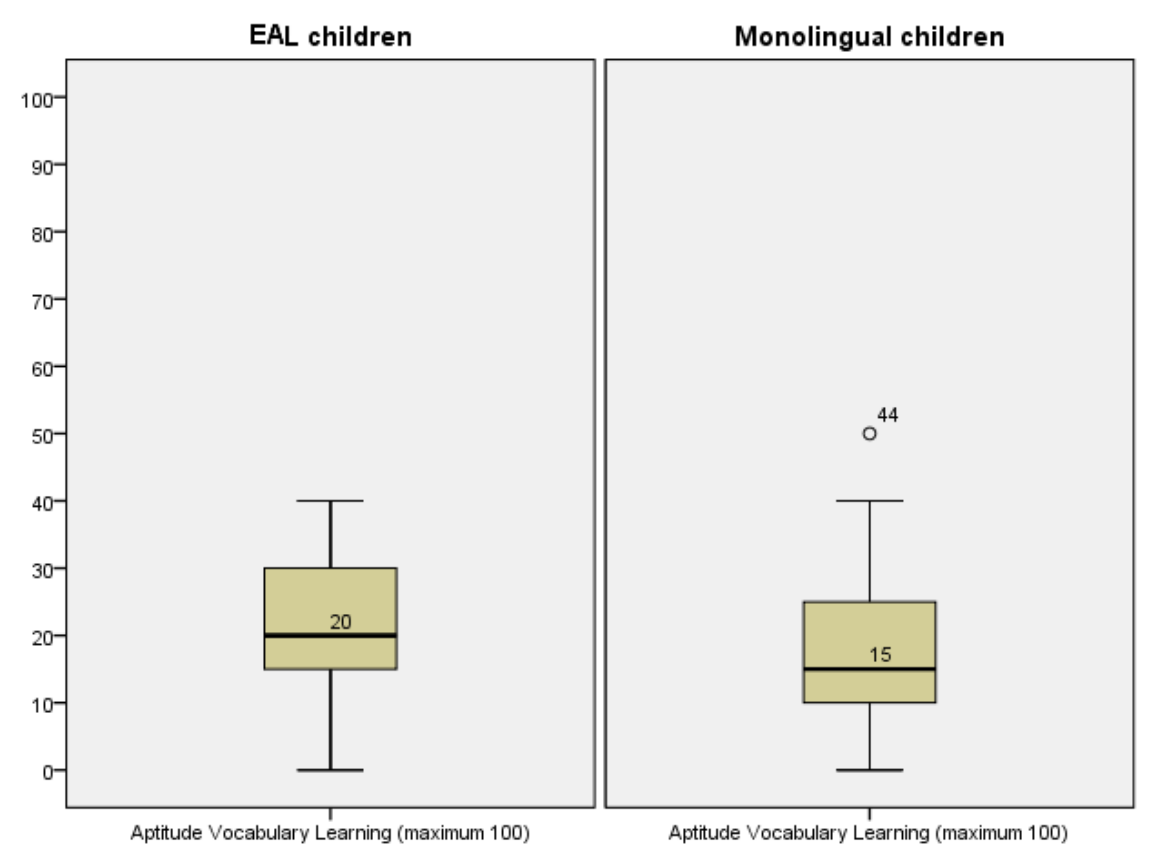


Table 1: Correlations between French proficiency and individual difference variables

\begin{tabular}{|l|l|l|l|l|}
\hline \multirow{2}{*}{} & \multicolumn{2}{|l|}{ EAL group } & \multicolumn{2}{l|}{ Monolingual group } \\
\cline { 2 - 5 } & MLA & LLAMA B & MLA & LLAMA B \\
\hline French proficiency & $\mathrm{r}=.678^{* *}$ & $\mathrm{r}=.560^{* *}$ & $\mathrm{r}=.303$ & $\mathrm{r}=.276$ \\
& $\mathrm{p}<.001$ & $\mathrm{p}=.004$ & $\mathrm{p}=.141$ & $\mathrm{p}=.202$ \\
\hline MLA & & $\mathrm{r}=494^{*}$ & & $\mathrm{r}=-.290$ \\
& & $\mathrm{p}=.014$ & & $\mathrm{p}=.179$ \\
\hline
\end{tabular}

Note: MLA = Metalinguistic awareness; ${ }^{*}$ significant at the .01 level; * significant at the .05 level 